\title{
REFLEXÕES SOBRE A RECATEGORIZAÇÃO REFERENCIAL SEM MENÇÃO ANAFÓRICA
}

\author{
Valdinar Custódio Filho*
}

Resumo: Este trabalho tem como objetivo descrever uma estratégia de construção referencial ainda pouco discutida: a recategorização sem menção anafórica. Consideramos que uma vertente dos estudos em referenciação tem procurado assumir com mais intensidade os pressupostos sociocognitivistas que coordenam as pesquisas em Linguística Textual na atualidade. A partir dai, surgem propostas explicativas que falam em favor de uma integração de múltiplos fatores para a construção do referente. Dentro desse processo, uma consequência esperada é a verificação de que o fenômeno não tem como permanecer circunscrito à ocorrência de sintagmas nominais. Về-se, assim, que a estratégia aqui descrita contribui para compreender o alargamento pelo qual o fenômeno da recategorização vem passando desde as reflexões iniciadas na década de 1990.

Palavras-chave: Referenciação. Recategorização. Anáfora.

\section{INTRODUÇÃO}

Os pressupostos sociocognitivistas investem no entrecruzamento de aspectos culturais e cognitivos para as explicações dos fenômenos relacionados à produção e transformação do conhecimento. A proposta da referenciação, assumindo tais pressupostos, representa o "modelo" mais bem preparado, até o momento, para dar conta da necessária explicitação de como o fenômeno da representação de entidades se efetiva, discursivamente, a fim de que a interação linguística se processe. Alguns estudos na área, procurando concretizar mais firmemente a aplicação dos pressupostos sociocognitivistas às análises, vêm discutindo desdobramentos ainda não considerados pela maioria dos pesquisadores (nacionais e internacionais).

Neste trabalho, intentamos contribuir com esses desdobramentos, falando em favor de uma estratégia de construção referencial ainda não devidamente descrita: a recategorização sem menção anafórica. Investimos na tese de que a construção da referência pode ser descrita sem que, necessariamente, o sintagma nominal seja o foco de todo o

\footnotetext{
* Professor Adjunto da Universidade da Integração Internacional da Lusofonia Afro-Brasileira UNILAB. Doutor em Linguística pela Universidade Federal do Ceará - UFC. Email: valdinarcustodio@gmail.com.
} 
processo. Assumir esse outro olhar implica levar em conta a integração de múltiplos fatores para a construção da referência.

$\mathrm{O}$ texto organiza-se em duas seções. Na primeira, apresentamos as duas tendências atuais nos estudos em referenciação, e explicitamos nossa vinculação à segunda tendência; vemos que, nessa tendência, os estudos focalizam o referente, mais que a expressão referencial. $\mathrm{Na}$ segunda seção, descrevemos a estratégia da recategorização sem menção anafórica, mostrando sua pertinência e traçando um paralelo entre ela e a estratégia da anáfora indireta.

\section{DUAS TENDÊNCIAS NOS ESTUDOS EM REFERENCIAÇÃO}

A fim de compreender em que panorama teórico se encontra o alargamento do fenômeno da recategorização conforme propomos neste trabalho, julgamos relevante, inicialmente, defender a ideia de que, no atual estágio das pesquisas em referenciação, os estudos podem ser vinculados a duas tendências. Advertimos, de antemão, que, longe de serem antagônicas, essas tendências são complementares, principalmente porque abraçam os mesmos pressupostos. O que muda é o foco de análise (e a consequente ampliação da noção de texto/discurso), no que diz respeito à participação e integração dos elementos linguísticos e não linguísticos na construção da referência.

\subsection{A primeira tendência}

A primeira tendência, seguida pela maioria dos estudos em referenciação ${ }^{1}$, tem como questão central a seguinte: de que maneira os usos referenciais (= expressões referenciais) elucidam/confirmam os postulados assumidos pela referenciação? Em linhas gerais, pode-se dizer que essa tendência parte das expressões referenciais acionadas em um texto para refletir sobre a natureza sociocognitivo-discursiva do fenômeno. Em virtude de uma saliência do caráter dinâmico atinente à

\footnotetext{
${ }^{1}$ Encontram-se exemplos de pesquisas dessa natureza na obra organizada por Koch, Morato e Bentes (2005) e na organizada por Cavalcante et al. (2007).
} 
construção dos objetos de discurso, foram abertas novas possibilidades investigativas, o que justificou a adoção da terminologia referenciação, em oposição a referência.

Há, nessa perspectiva, uma preocupação intensa com vistas ao entendimento do caráter "funcional" das expressões referenciais. Dessa forma, o referente deixa de ser apenas um objeto identificado no texto para ser um objeto que, podendo exercer várias funções (CIULLA; SILVA, 2008), é essencial para a configuração dos sentidos. Ganham destaque nesse quadro, por exemplo, as reflexões sobre o caráter argumentativo das expressões referenciais, como se vê em Koch (2005, entre outros) e Zavam (2007).

Os trabalhos associados à primeira tendência podem ser de dois tipos:

- estudos que propõem um quadro geral das estratégias referenciais, como os de Koch e Marcuschi (1998), Marcuschi (2000), Koch (2003) e Cavalcante (2003, 2004). Esses trabalhos têm, entre outros propósitos, o de mostrar propostas classificatórias das estratégias referenciais, para orientar as análises textuais;

- estudos que tratam de uma estratégia de referenciação específica, por exemplo, o encapsulamento (ou rótulo) ${ }^{2}$, a dêixis $^{3}$, a anáfora recategorizadora ${ }^{4} \mathrm{e}$ a anáfora indireta ${ }^{5}$.

Dentre as estratégias citadas, destacamos a recategorização anafórica e a anáfora indireta, sobre as quais apresentamos uma breve explicação.

A recategorização anafórica ocorre quando uma anáfora opera uma transformação no referente que vinha sendo construído até então. Vejamos um exemplo.

(1) Aconteceu em Minas: uma mulher traída cortou o cabelo da amiga... Pois é, foi assim mesmo. Uma descobriu que a outra tava

\footnotetext{
${ }^{2}$ Francis (2003) e Conte (2003).

${ }^{3}$ Cavalcante (2000) e Ciulla e Silva (2002).

${ }_{4}^{4}$ Apothéloz e Reichler-Béguelin (1995), Apothéloz e Chanet (2003), Tavares (2003), Matos (2005) e Lima (2007).

5 Apothéloz e Reichler-Béguelin (1999), Melo (2001), Gary-Prieur e Noailly (2003) e Marcuschi (2005).
} 
saindo com o marido da uma. Complicado? $\mathrm{Na}$ verdade não... se fosse só a clássica história de traição não teria nada demais. Mas a mulher traída era uma pessoa que queria (e sabia como) se vingar. Sabendo que o ponto fraco feminino são as melenas, não contou tempo: cortou tudo! Isso mesmo, fez com que a "amiga" fosse pra casa careca. As mulheres sabem como se vingar... Mas a história não acaba aqui. A careca entrou na justiça e processou a "cabeleireira louca" em 4 mil e 800 reais. Sim, e mais 600 reais pela peruca... Pois é... coisas do universo feminino. ${ }^{6}$

Em (1), um mesmo objeto de discurso, estabelecido pelas expressões sublinhadas, apresenta-se sob formas diferentes, o que configura um processo de recategorização lexical. Com o desenrolar da leitura, vão se acrescentando especificidades ao referente: além de uma mulher traída, somos informados de que ela era "uma pessoa que queria (e sabia como) se vingar", o que a levou a ser considerada uma "cabeleireira louca" (essa última expressão tem a função de apresentar a posição do enunciador a respeito desse referente). Vê-se, assim, que um mesmo objeto de discurso recebe diferentes formas referenciais, que modificam (recategorizam) seu status ao longo do texto.

Uma análise nesses moldes, portanto, pode tratar, entre outras coisas, da maneira como as expressões estabelecem a progressão referencial ou da forma como se depreende o projeto argumentativo de um enunciador a partir de suas escolhas referenciais. Poder-se-ia, ainda, avaliar os elementos pragmáticos e/ou discursivos que interferem na escolha dos determinantes (artigo definido, artigo indefinido ou pronome demonstrativo) das expressões referenciais.

Nos estudos iniciais sobre a recategorização (erigidos em torno do trabalho inaugural de Apothéloz e Reichler-Béguelin, 1995), consideravase que esse fenômeno estaria circunscrito aos casos de correferencialidade (anáfora direta), ou seja, aos casos de manutenção de um referente previamente apresentado. Contudo, os desdobramentos das investigações levaram ao entendimento de que a recategorização anafórica pode ocorrer em casos de encapsulamento e de anáfora indireta (ver, por exemplo, TAVARES (2003) e LIMA (2007)). As

\footnotetext{
${ }^{6}$ Disponível em http://www.psicologoneurotico.blogger.com.br/2004_07_01_archive.html. Acesso em 19 ago. 2008.
} 
contribuições tendem a considerar a recategorização como um processo mais amplo, passível de acontecer em qualquer estratégia anafórica.

A anáfora indireta talvez seja, das estratégias referenciais, a que mais se desenvolveu, em termos de explicações mais aprofundadas, a partir da proposta teórica da referenciação. Consiste na apresentação de um novo referente como se este já fosse conhecido. Isso decorre do fato de o contexto estabelecido até um determinado momento permitir uma gama de referentes potencialmente ativáveis, os quais, quando aparecem, já são esperados. É o que pode ser observado no exemplo a seguir, encontrado em Marcuschi (2005).

(2) Nos últimos dias de agosto... a menina Rita Seidel acorda num minúsculo quarto de hospital... A enfermeira chega até a cama...

Marcuschi comenta que a expressão "A enfermeira" não é correferencial a uma expressão anterior; entretanto, é apresentada como conhecida porque se trata de um elemento passível de ativação pelo esquema cognitivo que se instala com o item "quarto de hospital". Segundo o autor, não se trata, nesse caso, de uma anáfora ancorada em relações semânticas estritas, como são as relações meronímicas (relações parte/todo) ou outras relações semânticas "inscritas nos SNs definidos" (MARCUSCHI, 2005, p. 62), possibilidades contempladas pelas propostas limitadas a relações mais restritas. Trata-se de uma interpretação que demanda o conhecimento de esquemas cognitivos construídos socialmente. Os trabalhos sobre anáfora indireta têm como objetivo principal, portanto, esclarecer os aspectos contextuais (incluindo-se o aparato cognitivo) que interferem na elaboração e no processamento dessas ocorrências.

A partir do exposto, podemos dizer que a referenciação é uma proposta teórica que fortalece o "poder" da anáfora. Essa categoria não pode mais ser entendida nos limitados moldes da relação de identificação entre sintagmas presentes num texto. Ela é, na verdade, a unidade poderosa que revela um complexo trabalho sociocognitivo-discursivo de abordagem da realidade, passível de retomar elementos os mais diversos e de realizar múltiplas funções. Há, portanto, diversas (frutíferas) possibilidades de análise dentro dessa perspectiva. 
Assinalamos, contudo, que todas essas possibilidades são centralizadas na análise de expressões referenciais. Uma teoria que reforça o poder da anáfora (ou, mais precisamente, da menção anafórica) é, também, uma teoria da onipresença do sintagma nominal. Não se concebe, nesse panorama, que a construção dos referentes possa se estabelecer por estruturas e mecanismos não diretamente relacionados à menção referencial. Essa limitação, entre outras, tem estimulado avanços que fazem emergir o que denominamos segunda tendência dos estudos em referenciação.

\subsection{A segunda tendência}

A abordagem que caracteriza a segunda tendência parte do seguinte questionamento: de que maneira os vários elementos que participam da configuração textual (materialidade verbal e não verbal, aparato cognitivo, aspectos sócio-históricos e circunstanciais) são acionados para a construção de referentes? Além de entender como as relações entre as expressões referenciais podem ser tratadas sob o viés sociocognitivo-discursivo, importa saber como os referentes, construtos fundamentais para a produção dos sentidos, são elaborados, levando-se em conta que tal construção é passível de ocorrer dentro de uma dinâmica muito mais ampla, que não se limita, exclusivamente, ao universo das expressões referenciais.

Para nós, a segunda tendência marca, pertinentemente, outro movimento de investigação. Não se trata de buscar nos textos a confirmação dos postulados. Em vez de buscar exemplos (= expressões referenciais) que confirmem a teoria, parte-se dos usos, assumindo-se uma complexidade que não pode ser restrita ao papel dos sintagmas nominais, para ver como uma proposta de integração entre múltiplos fatores pode explicá-los; simultaneamente, admite-se que a própria análise pode mudar a proposta, tornando-a mais forte no que diz respeito a sua capacidade de explicação.

As diferenças já começam a ser notadas e vêm passando por descrições coerentes. Em torno das mudanças, está a convicção de que os postulados assumidos pelos que abraçam o paradigma sociocognitivista, os quais orientam uma concepção de texto como 
construto multifacetado, exigem compromissos dos pesquisadores, no que tange a uma investigação que privilegie, sempre e cada vez mais, a interação. É esse o espírito que anima as pesquisas da segunda tendência, as quais chegaram a alguns achados bastante instigantes, tais como:

- a consideração de que a recategorização é resultante da conjunção de várias porções cotextuais, e não apenas da "ligação" entre expressões referenciais (LEITE, 2007a, 2007b);

- a possibilidade de uma expressão referencial retomar um objeto de discurso presente em outro cotexto, o que fala em favor de uma anáfora intertextual (COSTA, 2007);

- a constatação de que elementos multimodais também promovem a construção dos referentes (MONDADA, 2005; CUSTÓDIO FILHO, 2009, 2011);

- a verificação de que a construção de referentes pode se dar sem a menção referencial.

É sobre este último tópico que desenvolvemos nossa discussão a partir daqui. Vemos, nessa ideia, uma grande contribuição que começa a ganhar corpo: trata-se de uma reorientação quanto à necessidade intrínseca de a referência ser manifestada, textual e discursivamente, apenas por expressões referenciais. A posição que vamos assumir, a partir de Cavalcante (2011), é contrária a essa, de modo que entendemos a atividade referencial como passível de ocorrer sem que haja um sintagma nominal específico para tal.

Tal possibilidade só passa a ser considerada quando se assumem, ou melhor, quando se levam em conta, nas análises, as consequências do princípio de que a construção do sentido é resultado da integração de múltiplos fatores (linguísticos e extralinguísticos). $\mathrm{Na}$ tendência majoritária, esse princípio é também considerado, mas ele (quando efetivamente aparece nas análises, o que nem sempre acontece) está sempre a serviço da elucidação da relação entre expressões referenciais. O que se está defendendo aqui é que a integração de múltiplos fatores indica possibilidades de estudo ainda não investigadas, mas que, se pararmos para pensar, podem ser consideradas como desdobramentos "naturalmente" esperados em relação ao que se vinha pesquisando. 
A título de ilustração, vejamos o exemplo a seguir, comentado por Cavalcante (2011).

(3) - Antes de começarmos, por favor, me diga uma coisa, o que o senhor fazia no emprego anterior?

— Eu era funcionário público!

- OK! O senhor pode contar até dez?

- É claro! Dois, três, quatro, cinco, seis, sete, oito, nove, dez, valete, dama, rei e ás.

50 piadas, de Donald Buchweitz.

A autora nos diz que, em (3), o referente "entrevista de emprego" (cuja depreensão é essencial para que se perceba o humor do texto) é construído sem que haja uma menção a ele. Contudo, vários elementos denunciam a sua "presença":

A fórmula de início da entrevista, "Antes de começarmos"; a alusão a um emprego anterior; a dêixis social ["o senhor"], indicando a forma de tratamento respeitosa, tudo isso se conjuga ao conhecimento comum que se adquiriu do ritual comunicativo de uma entrevista de emprego e favorece a instauração da referência (CAVALCANTE, 2011, p. 120-121).

A reflexão de Cavalcante, portanto, contempla uma ideia bastante cara ao que estamos chamando aqui de segunda tendência dos estudos em referenciação: as estratégias referenciais são mais complexas que o universo das expressões nominais. Segundo a autora (p. 122),

O referente, ou objeto de discurso, é uma entidade que emerge da própria interação e nem sempre se explicita por uma expressão referencial, quer se introduzindo no discurso, quer apenas se mantendo nele sem muitas alterações, ou quer se mantendo, mas se recategorizando. 
A aceitação dessa tese não significa desconsiderar as contribuições anteriores. Como bem esclarece a pesquisadora (2011, p. 122),

Não estamos negando, com esse pensamento, que, por outro lado, existam mecanismos de estabilização da referência, nem que o uso de uma expressão de introdução referencial ou de uma anáfora correferencial deva ser subvalorizado na reconstrução da coerência de um texto. Pelo contrário: sabemos que, no momento em que um referente é denominado por uma expressão referencial, sua lexicalização já contribui para estabelecer uma categoria em que ele foi enquadrado pelo enunciador (ver $\mathrm{KOCH}, 2002 \mathrm{a}$ ), e este será sempre um fabuloso recurso utilizado pelo falante para orientar o interlocutor quanto ao modo como se espera que ele desenhe o quadro referencial, a partir dos pontos de vista conduzidos no texto.

O comentário de Cavalcante salienta a não oposição entre as duas tendências. Como já dissemos, as duas propostas não precisam, necessariamente, se digladiar. As novas considerações não apagam ou desconsideram as estratégias referenciais mais "tradicionais", haja vista elas também se efetivarem a partir dos mesmos pressupostos. Entendemos que as novas reflexões, na verdade, só vêm fortalecer o paradigma pragmático-cognitivo-discursivo sobre a linguagem. Assumilo implica estar disposto a promover análises e reflexões que os levem efetivamente a cabo.

Esse desdobramento salienta a vocação da proposta da referenciação para respaldar e/ou fazer avançar os conceitos de sociocognição e de texto assumidos na atualidade. Levando-se em conta o panorama científico mais amplo, o quadro que aqui delineamos acerca dos avanços da referenciação confirma a ideia de que a Linguística está sempre disposta a encontrar explicações mais completas para sua teorização sobre os processos de significação. A fim de contribuir para tal empreitada, acrescentamos, à ideia da construção referencial sem menção, a consideração de que as recategorizações também podem ocorrer sem que seja necessário explicitá-las por meio de sintagmas nominais. É isso que discutimos na próxima seção. 


\section{SOBRE A RECATEGORIZAÇÃO SEM MENÇÃO REFERENCIAL}

A partir dos trabalhos que propõem desenvolver com mais coerência e sistematicidade a proposta inicial de Apothéloz e ReichlerBéguelin (1995) - dentre os quais se destacam Tavares (2003), Matos (2005), Cavalcante (2003), Lima (2007) e Leite (2007a, 2007b) -, temos visto evoluções que procuram dar conta da dimensão múltipla que o fenômeno da recategorização pode assumir. Nesse caminho, vislumbramos uma nova possibilidade de recategorização, a qual promove uma ruptura com a necessidade de amarras formais (a saber, a presença de uma expressão referencial) para que o processo se efetive. Optamos por nomear essa estratégia de recategorização sem menção referencial.

Como já dissemos, o percurso dos estudos em referenciação, no que diz respeito ao fenômeno da recategorização, caminhou na direção dos casos mais simples para os casos mais complexos ${ }^{7}$. Os pioneiros Apothéloz e Reichler-Béguelin ${ }^{8}$ abordaram os casos de recategorização como atrelados à correferencialidade, ou seja, presentes apenas em anáforas diretas. Grande avanço ocorreu com os acréscimos propostos por Leite (2007a, 2007b) e Lima (2007)9 , a partir do que se deu destaque à necessidade de entender a referência como resultado da conjunção de diversos elementos co(n)textuais.

Nossa contribuição caminha no sentido de reconhecer que, mesmo quando um referente é manifesto no texto por uma expressão nominal, não é obrigatório que as transformações sofridas se restrinjam ao universo das relações internominais de que porventura ele venha a participar.

\footnotetext{
${ }^{7} \mathrm{O}$ avanço dos estudos, entre outros méritos, destacou que os tais casos mais complexos não seriam formas especiais de referir, em oposição à prototipicidade dos casos mais simples. "Complexo", nesse contexto, não significa "mais raro", de modo que os casos de recategorização que extrapolam a correferencialidade são tão frequentes que podem ser considerados como constitutivos do processo. Defendemos que a recategorização sem menção referencial, apesar de ainda não ter sido devidamente descrita, também é constitutiva do processo referencial.

${ }^{8}$ Koch e Marcuschi (1998), no Brasil, adotaram abordagem semelhante à dos estudiosos franceses.

${ }_{9}$ Antes desses trabalhos, Cavalcante (2003) já mostrava que poderia haver recategorização tanto em anáforas indiretas quanto em encapsulamentos.
} 
Tratemos, mais uma vez, do exemplo (3). Nele, as expressões utilizadas para se referir ao candidato entrevistado são "o senhor", "eu" e "funcionário público". Não se pode afirmar que apenas elas dão conta da construção desse referente. Há, por exemplo, uma recategorização com vistas a que, no final, ele seja considerado pelo interlocutor como "preguiçoso" (o que, implicitamente, no texto, leva à conclusão de que o funcionário público é, de forma geral, negligente, relapso). A recategorização aludida não é apenas o resultado de uma cadeia coesiva relacionada ao referente "sujeito entrevistado"; ela emerge da integração de porções diferentes do cotexto, em conjunção com o aparato cognitivo ativado para a depreensão do humor.

Essa possibilidade abre uma perspectiva inovadora para o tratamento da referência, pois, aqui, não se trata de compreender como os diversos elementos responsáveis pela produção de sentidos no texto configuram uma determinada expressão referencial; trata-se de explicar como a recategorização, enquanto construção dinâmica, pode surgir a partir da integração desses elementos. Claro que, nesse panorama, a proposta da referenciação, tal como se vê na primeira tendência, deve passar por algumas reformulações. A fim de vislumbrarmos como essa renovação é necessária, façamos uma análise do texto a seguir:

(4) Que vergonha ver a atual prefeita censurar o uso de imagens de Ciro e Lula, grandes companheiros de Patrícia, no horário eleitoral! Será que essa prefeita tem vergonha de ver que Patrícia foi vice-líder de Lula no Senado??? Será que ela não se contenta em ver Lula longe dela, tal qual em 2004, quando o presidente estava com Inácio Arruda??? Antes era uma defensora da democracia, agora, no poder, se vestiu com as piores armas do autoritarismo e da censura! Liberdade de expressão JÁ! Patrícia é MULHER de RESPEITO e quer apenas ter o direito de mostrar a sua biografia, pena que a prefeita se [de]sespera com o passado histórico dela!

Texto recebido por e-mail.

O texto alude a uma situação ocorrida durante a campanha eleitoral para a prefeitura de Fortaleza (CE), em 2008: a coligação de apoio à prefeita Luiziane Lins (PT), candidata à reeleição, vetou 
judicialmente as propagandas da concorrente Patrícia Saboia (PDT) em que esta aparecia ao lado do presidente Lula e do então deputado Ciro Gomes. A partir do texto, emerge uma representação negativa de Luiziane, que, além de autoritária, seria uma competidora desleal. Tratase, portanto, de uma recategorização referencial, pois diz respeito à forma como o objeto de discurso se dá a conhecer no/pelo texto.

Interessa observar que a construção dessa imagem não está diretamente atrelada a nenhuma das expressões referenciais utilizadas para identificar o referente "Luiziane Lins" no texto. Se focalizarmos, por exemplo, a representação de "candidata autoritária", veremos que o texto menciona que Luiziane se veste com "as piores armas do autoritarismo"; ou seja, a representação não resulta de uma ligação entre expressões referenciais designadoras do objeto focalizado. Trata-se, na verdade, de algo muito mais básico - uma relação de predicação -, a qual não é devidamente tratada nos estudos da primeira tendência, em virtude de a ênfase na expressão referencial deixar de lado outras unidades de análise diferentes do que gira em torno do valor substantivo do sintagma nominal.

E o que dizer da representação de "candidata desleal"? Não há, neste caso, nem mesmo uma pista semântica (do tipo percebido em "autoritarismo") que justifique essa interpretação, porém ela é patente. Ocorre que, mais uma vez, a representação é construída a partir de inferências engatilhadas pelas predicações. Assumindo-se que a prefeita 1) censura o uso de imagens dos grandes companheiros de Patrícia; 2) tem vergonha de ver que Patrícia foi vice-líder de Lula no senado; 3) não se contenta em ver Lula longe dela; e 4) se desespera com o passado histórico de Patrícia, é possível estabelecer uma compreensão global em que se percebe claramente a intenção do enunciador em apresentar a candidata Luiziane como desleal.

Uma análise nesses moldes não pode ser feita quando o foco recai apenas sobre as expressões. O que se realça, aqui, é a complexidade das relações estabelecidas no texto, levando em conta as diferentes partes do cotexto e as diversas implicações contextuais. O procedimento continua sendo genuinamente sociocognitivo, contudo o aparato extratextual necessário para a produção dos referentes (e, consequentemente, dos sentidos) não se limita à identificação de associações entre a 
materialidade textual e os conhecidos esquemas (socio) $\operatorname{cognitivos}^{10}$. Trata-se de um procedimento muito mais difuso, mas não menos necessário.

$\mathrm{Na}$ verdade, a análise proposta reforça o postulado de que as operações textuais para construção da referência são específicas de cada interação, podendo os valores atribuídos aos objetos ser determinados de forma menos pontual. Se, inicialmente, já tínhamos assentada a noção de que não há valores axiológicos básicos dos itens linguísticos (como argumenta, por exemplo, ZAVAM, 2007), agora, temos que esses valores não se limitam ao uso de expressões referenciais específicas para tal fim, nem mesmo aos modificadores que possam acompanhar tais expressões. A trama textual pode passar por configurações as mais diversas e as mais complexas, o que, aliás, se coaduna com a concepção de texto atualmente assumida pela Linguística Textual ${ }^{11}$.

As recategorizações percebidas em (4) nos mostram, então, que há um referente manifesto no texto, cujas transformações não se limitam nem à cadeia correferencial de que faz parte nem às possíveis relações anafóricas indiretas. Aliás, é preciso destacar que, aparentemente, nosso comentário, tanto sobre (3) quanto sobre (4), poderia ser refutado se considerássemos as recategorizações mencionadas como anáforas indiretas.

Favoreceria tal abordagem o fato de se poder supor uma relação indireta entre as recategorizações sugeridas e possíveis âncoras textuais: em (3), uma das âncoras seria "valete, dama, rei e ás"; em (4), as âncoras seriam as diferentes predicações demonstradoras das atitudes de Luiziane $^{12}$. Contudo, a semelhança entre a anáfora indireta e o processo que aqui estamos considerando como ainda não devidamente investigado vai apenas até essa constatação. $\mathrm{Na}$ verdade, trata-se de dois fenômenos diferentes, porque têm orientação distinta. Se se quisesse aceitar como anáfora indireta o procedimento que descrevemos, seria necessário

\footnotetext{
${ }_{10}$ Veja-se, por exemplo, a diferença, no nível das relações ativadas, entre, de um lado, "prefeita desleal" e o conjunto de informações necessárias para essa representação, e, de outro lado, "a enfermeira" (anáfora indireta) e "quarto de hospital" (âncora), conforme exemplo (2).

11 Sobre concepções de texto, ver Cavalcante e Custódio Filho (2010).

${ }^{12}$ Considerar tais substratos de (4) como âncoras de uma anáfora indireta já seria, por si, um avanço, na medida em que o grosso das análises percebe uma relação muito mais pontual entre anafórico indireto e âncora.
} 
modificar a definição corrente do fenômeno (mesmo em suas versões mais "pragmática e cognitivamente" abrangentes).

Nas anáforas indiretas, ocorre um fenômeno que "termina" com a expressão referencial: o (con)texto vem estabelecendo um determinado conjunto de propriedades relevantes que permitem a manifestação de uma entidade "nova" como conhecida; o final do processo é a aparição da expressão que designa essa entidade. Isso é verdadeiro tanto para uma anáfora indireta mais "tradicional", tratada na literatura geralmente como "associativa", como a apresentada por Apothéloz (2003, p. 76), em (5), como para uma anáfora indireta mais "refinada" e mais inferencial (porque já vem recategorizada), como as apresentadas por Lima (2007), aqui exemplificadas por (6).

(5) Nós chegamos a uma cidade. A igreja estava fechada.

(6) Um antropólogo vai visitar uma aldeia no meio da floresta amazônica.

- Como você chegou até aqui? - pergunta-lhe uma índia, curiosa.

— Eu vim de helicóptero!

- Helicóptero?! O que é isso?

Ele tenta explicar de uma maneira bem simples:

—É um negócio que levanta sozinho...

— Ah! Eu sei... meu marido tem um helicóptero enorme!

Em (5), a anáfora indireta é explicada a partir de "conhecimentos gerais supostamente partilhados, exprimíveis sob a forma de proposições que colocam em relação referências genéricas (por exemplo: uma cidade tem uma igreja)" (APOTHÉLOZ, 2003, p. 76, grifo do autor). Em (6), há uma operação cognitiva muito mais refinada, pois é preciso operar "metaforicamente" sobre o texto a fim de perceber tanto a anáfora indireta estabelecida - decorrente das relações entre "helicóptero", "um negócio que levanta sozinho" e "um helicóptero enorme" - quanto o fato de que tal anáfora já vem recategorizada ("um helicóptero enorme" = genitália do marido da índia). Os dois processos, de (5) e de (6), são, 
contudo, marcados pela ênfase na explicação sobre por que as expressões aparecem como conhecidas, e terminam na manifestação dessas expressões.

As ocorrências citadas em (3) e (4) são de natureza distinta, pois as recategorizações sugeridas não aparecem no texto sob a forma de expressões referenciais (nem de outra natureza); contudo, ainda que não confirmadas lexicalmente, são bastante previsíveis e absolutamente necessárias para a compreensão dos propósitos discursivos dos enunciadores. Podemos dizer que elas continuam a expressar o fenômeno de construção da referência, contudo, em uma direção diferente da manifestada pelo procedimento anafórico indireto. Se, neste, há um caminho que vai do entorno sociocognitivo para a expressão, naquele, o caminho vai do cotexto para a elaboração sociocognitiva empreendida pelo interlocutor. Isso implica que tratar ocorrências do tipo de (3) e (4) como anáforas indiretas demandaria uma revisão das definições normalmente assumidas para essa estratégia. Por isso, preferimos nomear a estratégia aqui descrita como recategorização sem menção referencial.

Esse fenômeno é, para nós, uma estratégia referencial absurdamente frequente (e, na verdade, constitutiva do processo de interpretação), mas ainda pouco investigada. Mais uma vez, argumentamos que o quadro investigativo da segunda tendência se beneficia de explicações mais completas na medida em que considera a integração dos múltiplos fatores para a construção da referência. Essa decisão, como vimos, traça um caminho alternativo em relação às propostas que investem na onipotência da menção anafórica.

Podemos dizer que o poder da anáfora sintetiza todos os avanços da proposta da referenciação no âmbito da primeira tendência dos estudos. A ênfase no aspecto sociocognitivo do fenômeno possibilitou explicações bastante coerentes sobre como as necessidades contextuais configuram os usos linguísticos. A contribuição que apontamos mostra que os mesmos pressupostos orientadores da investigação dos usos linguísticos podem avançar ainda mais, possibilitando o alargamento do fenômeno da referenciação para além da relação anafórica convencional. A recategorização sem menção referencial, portanto, abre uma linha de investigação que pode contribuir para uma abordagem sistemática do complexo processo de produção e atribuição de sentidos via texto. 


\section{CONSIDERAÇÕES FINAIS}

Animados pela convicção de que o olhar sociocognitivo sobre os fenômenos textual-discursivos imprime algumas exigências investigativas, intentamos mostrar que os estudos da segunda tendência podem propor explicações que deem conta, com mais propriedade, da complexidade do fenômeno da referenciação. Neste trabalho, indicamos tal complexidade a partir de uma reflexão sobre a possibilidade de ocorrer a recategorização referencial sem o uso de uma expressão nominal específica para tal fim. Com isso, mostramos que as relações estabelecidas nos textos, com vistas à produção de sentidos, podem ocorrer por meio de estratégias diversas.

Consideramos que o movimento percebido em torno da segunda tendência pode ser considerado como um desdobramento esperado das investigações na área. Uma vez que referir é, também, dar sentido, fatalmente teríamos de ser levados a reconhecer que a constituição do sentido envolve "muitas coisas". Essas muitas coisas entraram indubitavelmente na agenda dos estudos sobre referenciação e, embora não exclusivamente, já dão a tônica de como serão as investigações futuras.

A partir daqui, já sabemos que a recategorização ocorre em diferentes situações. Para além disso, vislumbramos um quadro investigativo que saliente a natureza múltipla dos "aspectos" a serem recategorizados. Resta, portanto, descrever o "resultado" de tais recategorizações, ou seja, analisar e discutir os diferentes tipos de traços recategorizadores que podem ser atribuídos aos referentes. As perspectivas que se abrem atestam o caráter dinâmico do processo da referenciação e confirmam a posição fulcral que esse fenômeno ocupa nos estudos atuais da Linguística Textual. Tratemos, pois, de trilhar esse produtivo caminho teórico. 


\section{REFERÊNCIAS}

APOTHÉLOZ, D. Référer sans expression référentielle: gestion de la référence et opérations de reformulation dans des séquences métalinguistiques produites dans une tâche de rédaction conversationnelle. In: NÉMETH, E. (Org.). Pragmatics in 2000: selected papers from the 7th International Pragmatics Conference. v. 2. Antuérpia: International Pragmatics Association, 2001, p. 30 38.

. Papel e funcionamento da anáfora na dinâmica textual. Tradução de Mônica Magalhães Cavalcante e Camile Maria Botelho Regadas. In: CAVALCANTE, M. M.; BIASI-RODRIGUES, B.; CIULLA e SILVA, A. (Orgs.). Referenciação. São Paulo: Contexto, 2003. p. 53-84.

APOTHÉLOZ, D.; CHANET, C. Definido e demonstrativo nas nomeações. Tradução de Mônica Magalhães Cavalcante e Camile Maria Botelho Regadas. In: CAVALCANTE, M. M.; BIASI-RODRIGUES, B.; CIULLA e SILVA, A. (Orgs.). Referenciação. São Paulo: Contexto, 2003. p. 131-176.

APOTHÉLOZ, D.; REICHLER-BÉGUELIN, M.-J. Construction de la référence et strategies de designation. Tradução inédita de Mônica Magalhães Cavalcante. In: BERRENDONNER, A.; REICHLER-BÉGUELIN, M.-J. (Orgs.). Du sintagme nominal aux objects-de-discours. Neuchâtel: Université de Neuchâtel, 1995. p. 227-271.

. Interpretations and functions of demonstrative NPs in indirect anaphora. Journal of Pragmatics, v. 31, n. 3, p. 363-397, mar. 1999.

CAVALCANTE, M. M. Expressões indiciais em contextos de uso: por uma caracterização dos dêiticos discursivos. 2000. 205f. Tese (Doutorado em Linguística). Universidade Federal de Pernambuco, Recife, 2000.

. Expressões referenciais - uma proposta classificatória. Cadernos de Estudos Linguisticos, Campinas, n. 44, p. 105-118, jan./jun. 2003.

. Processos de referenciação: uma revisão classificatória. Comunicação apresentada no XIX ENANPOLL. Alagoas: UFAL, 2004.

. Referenciação: sobre coisas ditas e não ditas. Fortaleza: UFC, 2011.

CAVALCANTE, M. M. et al. (Org.). Texto e discurso sob múltiplos olhares. v. 2: referenciação e outros domínios discursivos. Rio de Janeiro: Lucerna, 2007.

CAVALCANTE, M. M.; CUSTÓDIO FILHO, V. Revisitando o estatuto do texto. Revista do Gelne, Teresina, v. 12, n. 2, p. 56-71, 2010. 
CIULLA e SILVA, A. A referenciação anafórica e dêitica - com atenção especial para os dêiticos discursivos. 2002. 104f. Dissertação (Mestrado em Linguística). Universidade Federal do Ceará, Fortaleza, 2002.

. Os processos de referência e suas funções discursivas: o universo literário dos contos. 2008. 201f. Tese (Doutorado em Linguística). Universidade Federal do Ceará, Fortaleza, 2008.

CONTE, M.-E. Encapsulamento anafórico. Tradução de Mônica Magalhães Cavalcante. In: CAVALCANTE, M. M.; BIASI-RODRIGUES, B.; CIULLA e SILVA, A. (Orgs.). Referenciação. São Paulo: Contexto, 2003, p. 177-190.

COSTA, M. H. A. Acessibilidade de referentes: um convite à reflexão. 2007. 214f. Tese (Doutorado em Linguística). Universidade Federal do Ceará, Fortaleza, 2007.

CUSTÓDIO FILHO, V. Aspectos multimodais envolvidos na construção da referência. In: CONGRESSO INTERNACIONAL DA ABRALIN. 6., 2009. Anais do ... João Pessoa: Ideia, 2009, p. 2927-2936 (CD-rom).

. Múltiplos fatores, distintas interaçoes: esmiuçando o caráter heterogêneo da referenciação. 2011. 329f. Tese (Doutorado em Linguística). Universidade Federal do Ceará, Fortaleza, 2011.

FRANCIS, G. Rotulação do discurso: um aspecto da coesão lexical de grupos nominais. Tradução de Mônica Magalhães Cavalcante, Valéria Sampaio Cassan de Deus e Thatiane Paiva de Miranda. In: CAVALCANTE, M. M.; BIASIRODRIGUES, B.; CIULLA e SILVA, A. (Orgs.). Referenciação. São Paulo: Contexto, 2003. p. 191-228.

GARY-PRIEUR, M.-N.; NOAILLY, M. Demonstrativos insólitos. Tradução de Camile Maria Botelho Regadas e Mônica Magalhães Cavalcante. In:

CAVALCANTE, M. M.; BIASI-RODRIGUES, B.; CIULLA e SILVA, A. (Orgs.). Referenciação. São Paulo: Contexto, 2003. p. 229-249.

KOCH, I. G. V. Desvendando os segredos do texto. 2. ed. São Paulo: Cortez, 2003.

. Referenciação e orientação argumentativa. In: KOCH, I. G. V.; MORATO, E. M.; BENTES, A. C. (Orgs.). Referenciação e discurso. São Paulo: Contexto, 2005. p. 33-52.

KOCH, I. G. V.; MARCUSCHI, L. A. Processos de referenciação na produção discursiva. D.E.L.T.A. [online], v. 14, n. especial, 1998. Disponível em:

$<$ http://www.scielo.br/scielo.php?script=sci_arttext\&pid=S0102445019980003 00012\&lng=en\&nrm=iso > . Acesso em: 17 jan. 2004. 
KOCH, I. G. V.; MORATO, E.; BENTES, A. C. (Orgs.). Referenciação e discurso. São Paulo: Contexto, 2005.

LEITE, R. L. Metaforização textual: a construção discursiva do sentido metafórico no texto. 2007. 212f. Tese (Doutorado em Linguística). Universidade Federal do Ceará, Fortaleza, 2007a.

. Da recategorização metafórica à metaforização textual. In:

CAVALCANTE, M. M. et al. (Orgs.). Texto e discurso sob múltiplos olhares. v. 2: referenciação e outros domínios discursivos. Rio de Janeiro: Lucerna, 2007b, p. 104-122.

LIMA, S. M. C. Recategorização metafórica e humor: uma proposta classificatória. In: CAVALCANTE, M. M. et al. (Orgs.). Texto e discurso sob múltiplos olhares. v. 2: referenciação e outros domínios discursivos. Rio de Janeiro: Lucerna, 2007. p. 74-103.

MARCUSCHI, L. A. Aspectos da progressão referencial na fala e na escrita do português brasileiro. In: GÄRTNER, E.; HUNDT, C.; SCHONBERGER, A. (Orgs.). Estudos de Linguistica Textual do português. Frankfurt e Main: TFM, 2000. p. 79-107.

Anáfora indireta: o barco textual e suas âncoras. In: KOCH, I. G. V.; MORATO, E. M.; BENTES, A. C. (Orgs.) Referenciação e discurso. São Paulo: Contexto, 2005. p. 53-101.

MATOS, J. G. As funcões discursivas das recategorizações. 2005. 142f. Dissertação (Mestrado em Linguística). Universidade Federal do Ceará, Fortaleza, 2005.

MELO, C. L. M. T. S. Anáfora indireta esquemática pronominal: uma anáfora coletiva genérica e coletiva restritiva. 2001. 143f. Dissertação (Mestrado em Linguística). Universidade Federal de Pernambuco, Recife, 2001.

MONDADA, L. A referência como trabalho interativo: a construção da visibilidade do detalhe anatômico durante uma operação cirúrgica. In: KOCH, I. G. V.; MORATO, E. M.; BENTES, A. C. (Orgs.). Referenciação e discurso. São Paulo: Contexto, 2005. p. 11-31.

TAV ARES, D. P. F. Processos de recategorização: uma proposta classificatória. 2003. 157f. Dissertação (Mestrado em Linguística). Universidade Federal do Ceará, Fortaleza, 2003.

ZAVAM, A. São axiológicas as anáforas encapsuladoras? In: CAVALCANTE, M. M. et al. (Orgs.). Texto e discurso sob múltiplos olhares. v. 2: referenciação e outros domínios discursivos. Rio de Janeiro: Lucerna, 2007. p. 123-143. 


\section{8}

Recebido em: 30/07/2012. Aprovado em: 30/10/2012.

Title: Discussion on referential recategorization without anaphoric expression Author: Valdinar Custódio Filho

Abstract: The purpose of this work is to describe a strategy of referential elaboration that is not yet well established: the recategorization without anaphoric expression. We consider that a branch of the studies in referenciation has searched to take on, with more intensity, the sociocognitive postulates, which inspire current researches in text linguistics. From this point, there are explanations that speak in favor of the integration among multiple factors in order to elaborate a referent. Consequential to this, we see now that referenciation cannot be related only to the presence of noun phrases. The strategy we describe here contributes to understanding the "enlargement" whereby recategorization has passed since the first studies in the 1990s.

Keywords: Referenciation. Recategorization. Anaphora.

Titulo: Reflexiones sobre la recategorización referencial sin mención anafórica Autor: Valdinar Custódio Filho

Resumen: Este trabajo tiene como objetivo describir una estrategia de construcción referencial aún poco discutida: la recategorización sin mención anafórica. Consideramos que una vertiente de los estudios en referenciación ha procurado asumir con más intensidad los supuestos sociocognitivistas que coordinan las pesquisas en Linguistica Textual en la actualidad. A partir de abi, surgen propuestas explicativas que bablan a favor de una integración de múltiples factores para la construcción del referente. Dentro de ese proceso, una consecuencia esperada es la verificación de que el fenómeno no tiene como permanecer circunscripto a la ocurrencia de sintagmas nominaleis. Se ve, así, que la estrategia aqui descripta contribuye para comprender el ensanchamiento por el cual el fenómeno de la recategorización viene pasando desde las reflexiones iniciadas en la década de 1990.

Palabras-clave: Referenciación. Recategorización. Anáfora. 